\title{
ESTUDIOS
}

\section{DE LA RAZÓN AL JUEGO: LA TEORÍA DEL CONOCIMIENTO DE LA ENFERMEDAD EN KARL JASPERS Y SU RECONSIDERACIÓN DESDE LA EPISTEMOLOGÍA ACTUAL*}

\author{
Ángel González de Pablo \\ Unidad de Historia de la Medicina, Facultad de Medicina \\ Universidad Complutense de Madrid
}

\section{RESUMEN}

A partir de la idea del Envolvente en tanto sistemática del pensamiento, se intenta caracterizar una posible teoría jaspersiana del conocimiento de la enfermedad. Dicha teoría gira en torno a los siguientes puntos: 1) La existencia de dos modos de conocimiento del enfermar: el directo u objetivo (basado en la causalidad, la no contradicción y la univocidad del lenguaje); y el indirecto o inobjetivo (basado en la acausalidad, la antinomia y la polisemia del lenguaje). 2) El establecimiento de una articulación no sincrética entre ambos por intermedio de la Razón. y 3) La consideración del todo de la enfermedad como realidad velada, como realidad que se anuncia alternativamente en esos dos modos articulados y no superponibles de conocimiento, pero que — en su totalidad - no puede enunciarse objetivamente.

Los distintos puntos de esta teoría se reconsideran, además, desde ciertas nociones de la actual teoría del conocimiento con el fin de conjeturar cuál podría ser la vigencia del pensamiento jaspersiano a finales del siglo XX.

PALABRAS CLAVE: Karl Jaspers, filosofía de la medicina, teoría de la medicina, epistemología de la medicina.

\section{SUMMARY}

Starting with the idea of the Encompassing as a system of thinking, I have tried to describe a possible Jaspersian theory of the knowledge of illness. This theory is based on the following points: 1) The existence of two methods of knowledge of the sick person: the direct or objective (based on

\footnotetext{
* Este trabajo ha sido realizado dentro del proyecto de la DGES PB-96-0631-C03-01.
} 
causality, non-contradiction, and the accuracy of language); and the indirect or unobjective (based on acausality, antinomy, and the polysemy of language). 2) The establishment of a non-syncretic articulation between the two through Reason (Vernunft). And 3) The consideration of the whole of the illness as a veiled reality, as a reality which is announced alternately in the two conected but not superimposed ways of knowing, although such a reality can never be enunciated in the form of a methodically fixed doctrine.

The various points of this theory are reconsidered, in addition, from the point of view of certain concepts belonging to current epistemology, so as to evaluate the degree of presence of Jaspersian thought at the end of the 20th century.

KEY WORDS: Karl Jaspers, philosophy of medecine, theory of medecine, epistemology of medecine.

\section{INTRODUCCIÓN}

Este trabajo busca dos objetivos principales: establecer, en primer lugar, cuál puede ser la teoría del conocimiento de la enfermedad que se desprende de la obra filosófica de Karl Jaspers (1883-1969); y, en segundo término, hacer una lectura actual de ella, conjeturando cuál podría ser su expresión desde la perspectiva de algunas nociones de la moderna epistemología.

Antes de entrar en materia, conviene dejar claro que, aunque Jaspers escribió sobre cuestiones relacionadas con la filosofía de la medicina ${ }^{1}$, un modelo teórico sobre la enfermedad no fue nunca formulado explícitamente por él. Lo que en estas páginas se va a mostrar en relación con la concepción teórica de la enfermedad es una especulación personal sustentada en la lectura de la obra jaspersiana y, especialmente, en su doctrina del Envolvente (das Umgreifende). La filosofía del Envolvente es una reflexión sobre el ser, entendida no en el sentido del establecimiento de un sistema del ser (Sein), sino más bien como una reflexión sistemática sobre el ente existente (Seiendes). En tanto tal es también, como puntualizó el mismo Jaspers ${ }^{2}$, una sistemática del pensamiento. Este será el sentido con el que aquí se utilizará dicha doctrina: como herramienta de pensamiento para el conocimiento de una cuestión específica cual es la de la enfermedad.

La filosofía de la medicina jaspersiana cuenta con una bibliografía crítica considerable ${ }^{3}$. Suele primar en ella el análisis de su pensamiento desde sus fuentes (Kant,

1 Entre los más significativos están: JASPERS, K. (1953a), «Die Idee des Arztes», Ärztliche Mitteilungen, 38, 476-479; JASPERS, K. (1953b), «Arzt und Patient», Studium Generale, 6, 435-443; JASPERS, K. (1958), «Der Arzt im technischen Zeitalter», Klinische Wochenschrift, 36, 1037-1043; y la sexta parte de JASPERS, K. (1946) Allgemeine Psychopathologie, $4^{\circ}$ ed., Berlin, Springer. Estos (aunque con la parte de la Allgemeine Psychopathologie resumida) y otros trabajos se recogieron en: JASPERS, K. (1986), Der Arzt im technischen Zeitalter, München, Piper.

2 JASPERS, K. (1983), Von der Wahrheit, $3^{\circ}$ ed., München, Piper, pp. 179-180.

3. Entre ellos pueden citarse: LICHTIGFELD, A. (1972), «The role of the boundary situation as an illuminating factor for Jaspers writings on psychopathology», Tijdschrift voor filosofie, 34, 92-106; 
Kierkegaard, Dilthey, Weber, Nietzsche...) o desde la comparación con otros autores con preocupaciones similares (Marcel, Heidegger, Camus, Goldstein...). Este trabajo va a intentar complementar estas consideraciones ofreciendo una perspectiva no hacia atrás — por así decirlo - hacia los fundamentos, sino hacia delante, hacia la proyección actual de la reflexión jaspersiana. Se hará, por tanto, un especial hincapié, primero, en reflejar los aspectos de su teoría de la enfermedad que gozan de mayor grado de vigencia y, segundo, en ofrecer una forma de pensar en ellos desde un estilo de pensamiento actual.

\section{EL CONOCIMIENTO DIRECTO DE LA ENFERMEDAD}

Partiendo de la doctrina del Envolvente 4 , puede considerarse que la enfermedad tiene en Jaspers una primera forma de acceso: la del conocimiento directo, objetivo o inmanente. En esta vía, la enfermedad puede ser considerada desde una serie de modos concebidos no como peldaños de una supuesta escalera de saber, sino más bien como distintas posibilidades en las que la enfermedad puede llegar a mostrarse ${ }^{5}$. Estos modos son el del simple ser (Dasein), el de la consciencia en sí (Bewusstsein überhaupt) y el del espíritu (Geist).

Desde el simple ser, la enfermedad tiene el carácter de amenaza contra la propia vida. Es vista como lo falso, lo que perjudica, limita, paraliza o vulnera. Y también como lo que impide la conservación y el desarrollo del existente ${ }^{6}$.

Koller, M. (1975), Der Arzt gegenüber der Ganzheit des Patienten: Mittragende Persönlichkeit oder Kurpfuscher der Seele?, tesis doctoral, Zürich; PRESAS, M.A. (1978), Situación de la filosofia de Karl Jaspers, Buenos Aires, Depalma; MEO, O. (1979), Psicologia e filosofia in Karl Jaspers, Firenza, Ariani; GOUHIER, A. (1987), «Lecture existentielle et lecture psychosomatique de la maladie». En: J.-M. PAUL (ed.), Le mal et la maladie, Nancy, Presses Universitaires de Nancy, 183-194; PreSAS, M.A. (1987), «Karl Jaspers y la enfermedad como experiencia del límite», Quirón, 18/2, 9-12; ENGELHARDT, D.v. (1987), «El médico y el paciente entre la ciencia y la humanidad en Karl Jaspers», Quirón, 18/2, 13-20; y GonZAleZ DE PABLO, A. (1987), La medicina en la obra de Karl Jaspers, Madrid, Ed. Complutense.

4 El Envolvente es la clavis clavium del discurso de Jaspers. Es aquello de donde somos y que por ello nunca resulta abarcado. Es aquello que es siempre más extenso, por extensa que sea nuestra concepción del objeto de nuestro conocimiento. JASPERS (1983), p. 37.

5 A lo largo de la evolución del pensamiento jaspersiano se produjo una variación respecto de la forma de pensar los modos del Envolvente. En su Philosophie aparecían más bien como sucesivos peldaños de la escalera del ser. En Von der Wahrheit, con la doctrina del Envolvente ya perfilada, adquirieron su definitivo carácter de posibilidades o espacios simultáneos en los que el ser puede manifestarse. SALAMUN, K. (1989), Karl Jaspers, trad. esp., Barcelona, Herder, p. 98.

6 «El simple ser (Dasein) concibe la verdad como lo conveniente (...) para su conservación y engrandecimiento (...) para su constante satisfacción». JASPERS, K. (1974), Existenzphilosophie, $4^{\circ}$ ed., Berlin, De Gruyter, p. 30. Sobre la concepción del Dasein, véase también: JASPERS, (1983), p. 49. 
Desde la conciencia en sí, la enfermedad es una entidad cognoscible por las diversas perspectivas de las ciencias naturales, conceptualizable en función de una serie de evidencias lógicas y formalizada en nociones precisas, objetivas y universalmente válidas mediante la acción del pensamiento lógico (Verstand $)^{7}$.

Desde el espíritu, por último, la enfermedad es una realidad dotada de una serie de significaciones interpretables en función de la compartición de una serie de ideas. Si la enfermedad en el modo anterior pertenecía al conocimiento de las ciencias de la naturaleza, aquí atañe al conocimiento de las ciencias del espíritu o ciencias humanas. Si la enfermedad en el modo anterior era tenida como un conocimiento científico universalmente válido, aquí el conocimiento científico (que da lugar a interpretaciones de la enfermedad) es sólo compartido — sólo se reconoce como tal— si se participa en los presupuestos de las distintas ciencias del hombre ${ }^{8}$. En la consciencia en sí, el pensamiento lógico (Verstand) buscaba la explicar la enfermedad (erklären); en el espíritu, el pensamiento lógico intenta comprenderla (Verstehen).

En resumen, tres nociones definen los tres modos complementarios del conocimiento objetivo de la enfermedad en el pensamiento jaspersiano: la inutilidad (lo vital), la evidencia (lo universal, lo científico-natural) y la convicción (lo compartido, lo científico-espiritual) 9 .

Por otro lado, y ahondando en la reflexión sobre la enfermedad dentro de la teoría del Envolvente, la expresión de estos tres modos en el hombre enfermo sólo se produce mediante la interrelación insoslayable de una serie de factores pertenecientes al yo del sujeto enfermo con otra serie de elementos pertencientes al no-yo (las entidades animadas o inananimadas que entran en conflicto vital con el hombre; las actitudes, opiniones y conocimientos de otros hombres que configuran el trato con la enfermedad; y el cúmulo de circunstancias que determinan la situación del sujeto, los cuales estarían dentro de lo que Jaspers denomina con el nombre genérico de mundo $(\text { Welt })^{10}$. El hombre enfermo cognoscible objetivamente sería, desde esta perspectiva, el resultado de la conjunción en una manera peculiar (alterada en comparación con la que se lleva a cabo en el hombre sano) del yo con el no-yo ${ }^{11}$.

\footnotetext{
7 «Existe un reino válido de la verdad, si bien angosto, delimitado con precisión y es el reino de los conocimientos exactos para la consciencia en general (...) La consciencia en sí, espacio de las ciencias, es para nosotros al mismo tiempo el espacio en que se hacen claros los juicios». JASPERS (1974), pp. 28-29. Sobre la concepción de la consciencia en sí, véase también: JASPERS (1983), pp. 48-49.

8 «Como espíritu, la verdad no es universalmente válida (...) para la evidencia del pensamiento lógico. La verdad del espíritu se afirma mediante el pertenecer a una totalidad que se esclarece a sí misma y se limita». JASPERS (1974), p. 30. Sobre el espíritu, véase también: Saner, H. (1982), Karl Jaspers in Selbstzeugnissen und Bilddokumenten, Reinbek, Rowohlt, p. 89.

9 JASPERS (1974), pp. 31-33.

10 No hay que olvidar que, de la misma forma que para Kant, el mundo en Jaspers nunca deviene objeto. Conocemos lo que está en el mundo, pero no el mundo. JASPERS (1974), p. 15.

11 Esta noción tiene como substrato la idea, muy arraigada en el pensamiento jaspersiano, de un supuesto estado originario prelógico en el que el hombre habría formado una 'unidad' con los otros hombres
} 
En el contexto de la conjunción con el mundo se produce, desde la perspectiva jaspersiana, la articulación de esos tres modos o posiblidades del conocimiento directo, la cual se guía por dos criterios: el del equilibrio y el de la apertura. El equilibrio, basándose en el reconocimiento de límites en los respectivos ámbitos de su conocimiento, impide que cualquiera de estos modos se absolutice sobre los demás. La percepción de los límites de los diferentes modos es, según Jaspers, evidente por parte del observador cuando éste es consciente de la existencia de las distintas formas de aproximación directa a la enfermedad. Así, el aspecto vital de la enfermedad queda limitado $-\mathrm{y}$ protegido frente a una posible consideración excesiva - por la visión explicativa científiconatural; a su vez, ésta queda limitada y protegida por la aproximación comprensiva científico-espiritual; la cual también queda limitada y protegida de cualquier exceso espiritualista por la toma en cuenta del anclaje biológico de la enfermedad $^{12}$. Complementariamente con el de equilbrio, el criterio de apertura impide por su parte que los conocimientos de cada modo puedan ser tenidos por definitivos y fuerza a su permanente cuestionamiento y cercioramiento ${ }^{13}$, dejando, además, franca la posibilidad de nuevas formas en el conocimiento directo de la enfermedad ${ }^{14}$.

Para la actual teoría del conocimiento la enfermedad continúa manteniendo, claro es, un primer abordaje desde el conocimiento objetivo o directo. Desde esta vía se siguen distinguiendo varios niveles de la realidad de la enfermedad, que son, a la par, niveles de organización y de conocimiento. Atlan sugiere los siguientes: el físico, el químico, el biológico, el fisiológico, el psíquico, el linguístico y el social ${ }^{15}$. En todo caso, desde la aproximación teórica no importa tanto, en resumidas cuentas, el número de estratos (que pueden resumirse en tres: el de las ciencias de la naturaleza, el de

\footnotetext{
y con el mundo. Tras producirse la escisión entre el yo y el mundo, el hombre se esforzaría en vano por la recuperación de la perdida unidad. A la cual Jaspers denomina, tomándolo de Schelling, «la participación cognitiva en la creación» (Mitwissenschaft mit der Schöpfung). JASPERS (1974), p. 24. Tan sólo en determinados instantes supremos (la enfermedad vivida como experiencia del límite podría ser uno de ellos) esa unión se haría certidumbre y el hombre vería en su ser el reflejo de aquel ser originario ahora perdido. JASPERS (1974), pp. 23-25.

12 En la carencia de límite de la aproximación comprensiva reside la crítica de Jaspers a Freud. Para aquél, éste habría llevado el psicoanálisis más allá de sus justos límites, convirtiéndolo en una pseudociencia natural. JASPERS, K. (195O) , «Zur Kritik der Psychoanalyse», Nervenarzt, 21, 465-468.

13 SALAMUN (1989), p. 99.

14 Sobre la posibilidad, que Jaspers siempre dejó abierta, de nuevos modos del Envolvente en su conjunto y, por lo tanto, también en la inmanencia del Envolvente, véase: JASPERS, K. (1981), «Reply to my critics». En: Paul Arthur SchILPP (ed.), The Philosophy of Karl Jaspers, $2^{\circ}$ ed., La Salle, Illinois, Open Court, 747-869; pp. 789-804.

15 Atlan, H. (1991), Con razón y sin ella. Intercrítica de la ciencia y del mito, trad. esp., Barcelona, Tusquets, p. 52.
} 
las ciencias de la vida y el de las ciencias del hombre) como el reconocimiento de la necesidad de establecerlos y diferenciarlos.

A partir del reconocimiento de esta necesidad, el problema epistemológico fundamental reside, como también supo ver Jaspers (que distinguía, como hemos visto, otros distintos), en la articulación de los diferentes niveles. Y esta articulación de la pluralidad se sigue rigiendo por los mismos principios que se observaban en el pensamiento de Jaspers: el de la apertura y el de la armonía.

El principio de apertura llama a la toma en consideración de que, en el estudio científico de la vida y, por tanto, de la enfermedad, siempre pueden surgir nuevos niveles de conocimiento asociados a nuevas formas de observación, experimentación y teorización, es decir a nuevas disciplinas (el caso de la biología molecular situada entre la química y la biología, es uno de los más significativos ${ }^{16}$ ).

El principio de la armonía intenta, completivamente, que el conocimiento científico de la enfermedad no quede absolutizado por el predominio de un nivel sobre los demás. Lo cual se traduce en la consideración simultánea en su conceptulización científica de postulados materialistas y espiritualistas, sin que ello suponga que todo es reducible a leyes físico-químicas o que haya que volver, por alguna $u$ otra vía, a referir la vida o la enfermedad a una suerte de espíritu o alma rectora añadida a la máquina corporal.

La práctica reduccionista consiste en separar los constituyentes de un todo para buscar en las propiedades de aquéllos la explicación de las propiedades de éste. Como tal, en tanto analítica, es indispensable para la investigación científica. Pero sólo hasta cierto punto. Llevada al extremo, el reduccionismo materialista imposibilitaría ver el papel que pueden tener, por ejemplo, el deseo o la voluntad en la expresión de la enfermedad.

La articulación armónica de los niveles de conocimiento de la enfermedad recoge la práctica reduccionista pero evitando su maximalización. La forma de hacerlo es la aplicación de lo que Atlan llama el «reducionismo débil» ${ }^{17}$, basado en la distinción de Peacocke de dos jerarquías en los organismos vivos: la de los sistemas y procesos, por un lado, y la de las teorías y conceptos, por otro. Para Peacocke, y en esto consistiría en último término el «reduccionismo débil» de Atlan, sólo los procesos serían reducibles a niveles inferiores, mientras que las leyes y los conceptos no lo serían, esto es, no podrían derivarse de las de un nivel inferior. Así, ideas específicas de la biología, como adaptación, evolución, función, etc. no pueden ser traducidas en términos de física o de química, aunque los procesos biológicos que estas leyes engloban sí se puedan reducir a procesos físico-químicos ${ }^{18}$. Así, por ejemplo, el estudio de

\footnotetext{
16 Véase sobre este punto: Morange, M. (1994), Histoire de la biologie moléculaire, París, La Découverte; en especial la tercera parte del libro, dedicada a la expansión de la biología molecular.

17 ATLAN (1991), pp. 59-60.

18 Peacocke, A.R. (1983), An Introduction to the Physical Chemistry of Biological Organization, Oxford, Clarendon, pp. 268-272.
} 
la enfermedad a nivel biológico tiene en cuenta las leyes de la física y de la química, pero necesita además de información adicional; de la conjunción de esta información con las leyes de los campos más fundamentales se derivan leyes específicamente biológicas que delimitan el conocimiento a este nivel ${ }^{19}$.

La articulación armónica hace considerar, por tanto, el reduccionismo débil (de los procesos) en la enfermedad, pero evita el reduccionismo fuerte (de las leyes y conceptos). Además, complementariamente, la articulación armónica fuerza a tener presente los factores psicológicos del enfermar sin por ello caer en el extremo del espiritualismo, que haría a la enfermedad achacable a la afectación de un principio anímico rector añadido al cuerpo y con repercusiones sobre éste. Y, por el mismo razonamiento, como se verá, este criterio permite considerar los aspectos sociológicos sin caer en el sociologismo.

La adecuada consideración de los factores psíquicos y rechazo del psicologismo o espiritualismo parten de la consideración del organismo humano como sistema autoorganizativo ${ }^{20} \mathrm{o}$, si se prefiere, como un sistema complejo adaptativo ${ }^{21}$, en donde se contempla que las propiedades específicas surgen - emergen - de la organización del sistema en diferentes niveles de integración. Las propiedades psíquicas emergerían, por tanto, del sistema humano - sano o enfermo - al alcanzar éste los niveles organizativos superiores.

La idea de la autoorganización se ha ido elaborando desde los años sesenta a partir de la teoría de la información, de la termodinámica, de la cinética química y, más recientemente, merced a la teoría de la inteligencia $\operatorname{artificial}^{22}$. Esta teoría entiende al organismo viviente como una totalidad compleja estructurada jerárquicamente en distintos niveles de integración progresivamente complejos, los cuales se van alcanzando mediante la conversión en información de una serie de perturbaciones aleatorias del medio ambiente englobadas bajo el nombre genérico de ruido ${ }^{23}$.

19 Al respecto, véase: Gell-MAnN, M. (1995), El quark y el jaguar. Aventuras en lo simple y lo complejo, trad. esp., $2^{\circ}$ ed., Barcelona, Tusquets, pp. 130-131.

20 Atlan, H. (1979), Entre le cristal et la fumée. Essai sur l'organisation du vivant, Paris, Seuil, pp. 91-99.

21 Gell-ManN (1995), pp. 34-39.

22 Para una detallada descripción de la teoría de la autoorganización, véase ATLAN (1979), pp. 13-130. Una recopilación de aportaciones más recientes se encuentra en ATLAN (1991), pp. 106-107. Para una imagen multidisciplinar de los sistemas complejos, véase: LEWIN, R. (1995) Complejidad. El caos como generador de orden, trad. esp., Barcelona, Tusquets. Entre las obras más actuales que abordan esta cuestión desde la perspectiva específicamente biológica, uno de los trabajos más interesantes es el de Kauffmann, S. (1995), At Home in the Universe. The Search For Laws of Self-Organization and Complexity, New York, Oxford University Press.

23 PARIS, C. (1994), El animal cultural. Biología y cultura de la realidad humana, Madrid, Crítica, pp. 211-213. 
El ruido, aleatorio porque las causas de su aparición no tienen nada que ver con la cadena de fenómenos que ha constituido la historia del sistema hasta el momento de su intersección, si se encuentra con el sistema produce errores (modificaciones) en alguno de sus niveles. Si estos errores no acaban con el sistema, los elementos modificados a un nivel son integrados en el siguiente y en esta integración pierden su carácter de errores transformándose en información. La conversión del error a un nivel en información a otro superior se debe a que los errores integrados aumentan la variedad del nivel superior (que pasa a englobar entonces elementos inferiores modificados y no modificados), convirtiéndole en más complejo y capacitándole para interaccionar mejor con el ruido al situarle en un estado óptimo entre el orden total y el desorden absoluto ${ }^{24}$. Así, por ejemplo, para la célula que resulta afectada por la acción de las perturbaciones aleatorias externas, el ruido es negativo; pero, para el órgano, este ruido celular puede ser positivo (si no mata a al célula), en tanto que puede aumentar el grado de variedad de sus actividades regulares ${ }^{25}$.

Mediante la integración de estos elementos erróneos convertidos en información se explica la aparición de nuevas propiedades a un nivel más global en relación con el nivel más elemental en donde estos elementos erróneos no estarían integrados. Aparecerían, así, como mantiene Atlan ${ }^{26}$, propiedades (químicas) de las moléculas, nuevas respecto de las propiedades (físicas) de los átomos; propiedades (biológicas) de las células vivas, nuevas respecto de las propiedades de las moléculas; propiedades (fisiológicas) de los organismos, nuevas respecto de las propiedades celulares; propiedades (psicológicas) de la mente, nuevas respecto de las propiedades neurofisiológicas del sistema nervioso; propiedades (sociológicas) de los grupos humanos nuevas respecto de las propiedades de los individuos ${ }^{27}$. En resumen: la idea de la autoorganización sostiene, en el marco del principio de la complejidad por el ruido, que, en los sistemas complejos, el orden (las distintas propiedades de los distintos niveles) emergería del dominio de azar (el ruido) por el azar (el estado entre el orden total y el desorden absoluto de los distintos niveles y del sistema en su conjunto). El orden además es pasajero, pues la organización es un proceso ininterrumpido de desorganizaciónreorganización, en tanto que el sistema puede generar ruido a partir de la información integrada, el cual puede volver a interactuar con el sistema y así indefinidamente ${ }^{28}$.

La autoorganización también puede servirnos para acercarnos a la comprensión de la enfermedad. En la enfermedad, el ruido daría lugar a un error excesivo de los

\footnotetext{
24 ATLAN (1979), pp. 56-57.

25 Ibidem, p. 70. O, dicho en palabras de Gell-Mann: «La ciencia de la biología es mucho más compleja que las leyes fundamentales de la física porque gran parte de las regularidades que se observan en la biología terrestre proceden tanto de sucesos casuales como de dichas leyes». GELL-MANN (1995), p. 133.

26 ATLAN (1991), p. 69

27 Ibidem, pp. 69-70.

28 ATLAN (1979), p. 91.
} 
elementos de determinado nivel del sistema (las células, por seguir con el ejemplo anterior). Este error, si no acaba con el sistema, podría ser integrado a un nivel superior (orgánico, en este caso), pero la complejidad a que daría lugar a este nivel no sería la óptima entre el orden y el desorden, sino que conduciría a otra con un mayor grado de desorden del considerado óptimo, lo cual le haría menos apto para asimilar el ruido del medio. La salud y la enfermedad consisitirían así, si este punto de vista es válido, en el mismo proceso de destrucción-reconstrucción por el error. El error es en ambas situaciones un error, pero en un caso (en la enfermedad) se comportaría como una catástrofe y en otro (en la salud) como un milagro ${ }^{29}$.

Recapitulando lo hasta ahora dicho, puede decirse que, a pesar de las diferencias en las perspectivas con que se contemplan, dos son los rasgos de la concepción del conocimiento objetivo de la enfermedad en el pensamiento de Jaspers que se siguen manteniendo en las delimitaciones actuales del conocimiento científico del enfermar:

1. El reconocimiento de una serie de modos en dicho conocimiento inmanente, los cuales están interrelacionados de forma abierta (esto es, que pueden llegar a delimitarse otros nuevos) y armónica (evitando el predominio de unos sobre otros). En Jaspers los límites entre ellos se establecen de una forma subjetiva a partir del sentimiento de su evidencia por parte del observador ${ }^{30}$. En la actual teoría del conocimiento, esos límites tienen una fundamentación más objetiva a través, entre otras nociones, del reduccionismo débil y de la idea de la autoorganización.

2. El hincapié en la importancia que tiene lo externo en la conformación de los distintos modos de aproximación al conocimiento objetivo del enfermar. $\mathrm{La}$ variada y variable influencia del medio se presenta en Jaspers a través de la noción de mundo (en donde la figura del otro, del observador, tiene una especial significación). En el pensamiento actual, uno de los conceptos que mejor se adecúan para expresar esa configuración por lo externo es el ruido (su aleatoriedad y su función de desorganizador-reorganizador serían sus cualidades más significativas).

29 Ibidem, pp. 57-58.

30 En relación con las posibles deficienicias de esta subjetividad, recuérdense las críticas a los límites del comprender (das Verstehen) hechas a su metodología psicopatológica, los cuales se suelen considerar excesivamente rigurosos debido, sobre todo, a la equiparación jaspersiana entre lo comprensible y lo comprendido. Entre la reciente bibliografía sobre la psicopatología de Jaspers, puede verse en relación con este punto: BASSLER, W. (1990), Psychiatrie des Elends oder das Elend der Psychiatrie. Karl Jaspers und sein Beitrag zur Methodenfrage in der klinischen Psychologie und Psychopathologie, Würzburg, Königshausen \& Neumann, p. 180 


\section{LA POSIBILIDAD DE OTRAS FORMAS DE CONOCIMIENTO}

La realidad de la enfermedad no se agota para Jaspers en su conocimiento directo o inmanente. Dicha limitación del conocimiento objetivo se fundamenta en una de las referencias básicas en su pensamiento, cual es la distinción kantiana entre el mundo de la apariencias causalmente determinado y el mundo inteligible y no causalmente determinado de la libertad ${ }^{31}$. Partiendo de esta dicotomía, para Jaspers el ser empírico racional (en tanto simple ser, consciencia en sí y espíritu) no puede nunca abarcar la totalidad de las facetas del hombre, pues éste es también Existencia (Existenz) inobjetiva e inobjetivable.

En sintonía con lo anterior, la enfermedad - aparte de un conocimiento causal dirigido a objetivarla como lo empíricamente nocivo (desde la simple existencia), como lo comprobable de forma universalmente válida (desde la consciencia en sí) y como lo comprensible dentro de unas convicciones comunes (desde el espíritu) - es susceptible también de una aproximación inobjetiva o indirecta (desde la enfermedad como llamada a la Existencia posible o Existenz), en la que se prima el conocimiento desde la libertad o, lo que es lo mismo, desde la paradoja ${ }^{32}$.

La teoría del conocimiento, en sus diferentes tendencias, sigue manteniendo en la actualidad la posibilidad de otras formas de conocer la realidad distintas de las del pensamiento causal. Si en Jaspers esa eventualidad partía de la elaboración de la doctrina kantiana de las ideas, aquí se fundamenta en la indecidibilidad (no demostrabilidad) de la racionalidad de la realidad.

Si la realidad fuera racional, el conocimiento racional sería la única forma de conocerla, pues la razón se basa en el principio lógico de la no contradicción: «no es el caso que A y no A»o «A no puede ser A y no A a la vez y bajo el mismo aspecto».

Esta pretensión de exclusividad de la racionalidad sobre la realidad empezó a tambalearse para la filosofía de la ciencia a raíz de las conclusiones del lógico mate-

31 Entre la reciente bibliografía en relación con el débito kantiano del pensamiento de Jaspers, pueden verse: Walker, Ch. (1993a), «Karl Jaspers as a Kantian psychopathologist, I The philosophical origins of the concept of form and content», History of Psychiatry, 4, 209-238; WALKER, Ch. (1993b), «Karl Jaspers as a Kantian psychopathologist, II The concept of form and content in Jaspers' psychopathology», History of Psychiatry, 4, 321-348; y WALKER, Ch. (1994), «Karl Jaspers as a Kantian psychopathologist, III The concept of form in Georg Simmel's social theory: a comparison with Jaspers», History of Psychiatry, 5, 37-70.

32 La verdad en la dimensión de la Existencia no tiene ya ningún asidero estable: «Donde no me es dado ningún efecto verificable de una verdad pragmática, ninguna certeza experimentable del pensamiento lógico, ninguna oculta totalidad del espíritu, allí llego a la verdad en cuanto franqueo toda inmanencia del mundo». JASPERS (1974), p. 32. 
mático Kurt Gödel en la década de los $30^{33}$. De entre ellas, las más relevante para lo que aquí se trata es la relativa a la indecidibilidad: dado un sistema de axiomas matemáticos, siempre habrá proposiciones indecidibles sobre la base de tales axiomas. $\mathrm{O}$, en otros términos, hay proposiciones de las que, en principio, no puede demostrarse su verdad o falsedad ${ }^{34}$.

Pero previamente Wittgenstein, ya había abordado este problema. En su Tractatus (1922) había afirmado que al signo de la negación no le correspondía nada en la realidad. Esto es: que la negación no era simétrica de la afirmación, puesto que si bien la afirmación describía lo que existe, la negación respondía a la actuación de nuestro pensamiento sobre lo que existe ${ }^{35}$.

De donde resulta, como infiere Atlan ${ }^{36}$, que cualquier proposición que tiene una negación en su enunciado ( A no puede ser a la vez A y no A») es siempre el producto de una maniobra de nuestro pensamiento y no describe nunca la realidad tal y como es. Si esto es así, implicaría que el principio de no contradición no es real, con lo cual la realidad podría ser contradictoria. Pero al deducir esta consecuencia estamos empleando el principio de la no contradicción. Por consiguiente, el principio de la no contradicción no describe la realidad, pero la prueba de que no lo hace, al estar fundada en él, tampoco concierne a la realidad. Con lo cual, el que la realidad sea sólo racional es indecidible, pero esta indecidibilidad es también indecidible y la indecidibilidad de la indecidibilidad también lo es, y así ad nauseam. De donde se puede deducir que la realidad puede ser racional, pero también puede no serlo; el conocimiento científico, en tanto racional, puede conocer la realidad, pero el conocimiento paradójico también ${ }^{37}$.

De todo esto se desprende que el conocimiento de una realidad específica como pueda ser la de la enfermedad tiene dos accesos posibles: el racional (derivado del pensamiento lógico y causal), basado en el estudio de la enfermedad a partir del principio de la no contradicción, al cual y a sus niveles ya hemos dedicado las anteriores páginas; y el paradójico o arracional, para el cual el conocimiento de la enfermedad se

33 La utilización del teorema de la indecidibilidad de Gödel no ha dejado de tener vigencia. Recientemente, Penrose se ha basado en él para demostrar que el entendimiento consciente no es computacional. Penrose, R. (1996), Las sombras de la mente, trad. esp., Barcelona, Crítica.

34 GELL-MANN (1995), p. 56.

35 «Pero es importante que los signos 'p' y 'no p' puedan decir lo mismo. Pues esto indica que nada corresponde en la realidad al signo 'no'. Que en una proposición entre una negación no es característico de su sentido (no no $\mathrm{p}=\mathrm{p}$ ). Las proposiciones ' $\mathrm{p}$ ' $\mathrm{y}$ 'no $\mathrm{p}$ ' tienen sentido opuesto pero les corresponde una y la misma realidad». WITTGENSTEIN, L. (1981), Tractatus Logico-Philosophicus, ed. bilingüe en alemán y castellano, $5^{\circ}$ ed., Madrid, Alianza, pp. 80-81 (4.0621).

36 ATLAN (1991), pp. 178-180.

37 La vida cotidiana también nos da algunos ejemplos sobre los problemas que puede causar el atenimiento estricto, sin un cierto espíritu crítico, al principio de la no contradicción. $C f$. PAULUS, J.A. (1994), Pienso, luego río, trad. esp., Madrid, Cátedra, pp. 27-29. 
realiza desde una experiencia sensible no conformada previamente por un esquema lógico que restringe su campo de posibilidades a lo no contradictorio. A diferencia de la irracionalidad, la arracionalidad sí usa el pensamiento lógico, pero a otro nivel distinto - más allá del explicar y del comprender — al empleado por la racionalidad. Las modos inmanente (causal y objetivo) y trascendente (no causal y no objetivo) de Jaspers siguen estando, así, presentes en la dicotomía racional/arracional.

\section{EL CONOCIMIENTO INDIRECTO DE LA ENFERMEDAD}

Por consiguiente, ya sea - como Jaspers - partiendo de Kant, ya sea de Wittgenstein, como la filosofía del conocimiento actual tiende a hacer, el hecho es que se reconoce la posibilidad de otro tipo de conocimiento de la realidad aparte del directo: el conocimiento indirecto o arracional.

El lenguaje de este conocimiento indirecto, del conocimiento esclarecedor, tiene en Jaspers dos rasgos: su carácter simbólico o cifrado y su expresión paradójica o contradictoria ${ }^{38}$. Busca, llevando al límite el lenguaje objetivo, del que no puede evitar servirse, pasar a su través hasta alcanzar un nivel simbólico, es decir, otro nivel de percepción distinto del habitual. Para ello, el lenguaje esclarecedor debe moverse en parejas de contradicciones lógicas (temporalidad-eternidad, soledad-comunicación, libertaddependencia... son algunas de las más recurridas). Con ellas se deshace lo que las afirmaciones establecen, sin limitarse a una simple negatividad. Con ellas además se utiliza lo explícito para hacer ver lo no-dicho, convirtiendo el lenguaje en símbolo o cifra (Chiffer o Chiffre) de lo que no puede decirse.

El acercamiento a la enfermedad desde el símbolo y la paradoja fue en Jaspers inevitable. Jaspers fue un enfermo prácticamente durante toda su vida. A los 18 años se le diagnosticó un proceso pulmonar crónico y a partir de entonces la enfermedad y sus condicionantes formaron parte de su vida ${ }^{39}$. Este trato permanente con ella quedó en parte recogido en su «Historia de la enfermedad» (Krankheitsgeschichte) (1938). En sus páginas Jaspers dejó testimonio de la constante inmersión en la paradoja que la vivencia de la enfermedad conlleva: «Puedo negar el ser enfermo, oponerme a ello como algo totalmente extraño (...) O puedo identificar la enfermedad conmigo mismo. El ser enfermo queda transformado en este segundo caso en un elemento constitutivo de mi esencia (...) Ambas posturas son, en su rigidez, falsas. Pero inevitablemente se tocan alguna vez esos extremos en la lucha por la aceptación de la

\footnotetext{
38 En torno al lenguaje de lo que en este trabajo llamamos conocimento indirecto, véase el modo en que Jaspers concibe el esclarecimiento de la Existencia: JASPERS, K. (1973), Philosophie, 3 vols., $4^{\circ}$ ed., Berlin, Springer, II, pp. 9-18. También puede consultarse: REMOLINA VARGAS, G. (1972), Karl Jaspers en el diálogo de la fe, Madrid, Gredos, pp. 94-96.

39 JASPERS, K. (1977), Philosophische Autobiographie, $1^{\circ}$ ed. 1957, München, Piper, pp. 13-14.
} 
enfermedad. Esta aceptación es, en definitiva, una tarea insoluble. No es posible en estado puro. Siempre hay algo que no casa. La finitud del hombre, su radical dependencia, se le hace al enfermo no sólo más consciente que al sano, sino también cualitativamente distinta. No puede abandonarse ni un sólo día a su simple existencia» ${ }^{40}$.

La paradoja fue, asimismo, el medio del que Jaspers se sirvió para adentrarse en la enfermedad en sus estudios patobiográficos ${ }^{41}$. En ellos se parte de la noción nietzscheana del hombre como animal no consolidado ${ }^{42}$. Esta no consolidación supone la posibilidad de la perfectibilidad, pero se acompaña siempre de la presencia de la fragilidad (Gebrochenheit). La enfermedad acrecienta la fragilidad del hombre, pero paradójicamente al hacerlo le abre la vía a otra forma de perfectibilidad. La enfermedad experimenta desde esta perspectiva una transvaloración (Umwertung): sano es aquello que conduce a hacer realidad la potencialidad del hombre; la enfermedad, si conduce a una actualización de estas potencias, como en el caso de Hölderlin y Van Gogh, se transforma en un síntoma de salud. Contrariamente, todo lo que impide esa realización —y la enfermedad también puede llevar a este resultadopasa a ser considerado como lo verdaderamente enfermo ${ }^{43}$.

A partir de su visión desde la paradoja y la contradicción, la enfermedad puede ser percibida de otra forma distinta de la objetiva y causal. Experimenta, así, su conversión en cifra (Chifferwerden), quedando transmutada en un objeto transcendente no cognoscible sino tan sólo esclarecible.

En tanto símbolo, la enfermedad se apropia en Jaspers del perfil de situación límite (Grenzsituation) o situación inmodificable en la que el hombre, cuando la vive conscientemente, choca con los límites básicos de su ser, adquiriendo conciencia de la incertidumbre y de las limitaciones de su vida ${ }^{44}$. La enfermedad-símbolo, como experiencia del límite, deviene trasunto, cifra, de la posible Existencia: «experimentar situaciones límite y existir (Existieren) es la misma cosa» ${ }^{45}$. Se transmuta así en la vía para el fugaz atisbo del sí mismo, ese núcleo no objetivable de la interioridad de cada

40 JASPERS, K. (1967), «Krankheitsgeschichte». En: JASPERS, K., Schicksal und Wille. Autobiographische Schriften, ed. de H. SANER, München, Piper, 109-142; p. 142.

41 En estas patografías, Jaspers se preocupó especialmente por averiguar cuál podría la relación entre enfermedad y creación genial. JASPERS, K. (1949), Strindberg und Van Gogh. Versucht einer vergleichenden pathographischen Analyse, $3^{\circ}$ ed., München, Piper, p., 174.

42 Nietzsche, F. (1954-1956), Werke in drei Bänden, ed. de K. ScHLECHTA, München, Hauser, II, p. 623 (62); JASPERS, K. (1959), Allgemeine Psychopathologie, $7^{\circ}$ ed., Berlín, Springer, p. 631.

43 Las semejanzas entre esta consideración de la enfermedad y la noción de gran salud (grosse Gesundheit) del superhombre (Übermensch) de Nietzsche son bastante claras. Cf. NIETZSCHE (1954-1956), II, p. 257 (382).

44 Las situaciones límite «no cambian, sólo se modifican en apariencia (...) son como un muro ante el que chocamos, ante el cual fracasamos. No podemos cambiarlas, sólo esclarecerlas, sin poder explicarlas o deducirlas a partir de algún otro». JASPERS (1973), II, p. 203.

45 JASPERS (1973), II, p. 204. 
cual, en donde se consigue el impulso para el repensamiento de sí y su culminación en nuevas actitudes y realizaciones, que en determinadas personalidades - como las de Hölderlin, Van Gogh, el mismo Nietzsche - pueden alcanzar incluso la genialidad ${ }^{46}$.

Por último, no se puede olvidar que en el pensamiento de Jaspers la fugitiva vivencia de la enfermedad como experiencia del límite, estrictamente íntima y singular, y el consiguiente entreverse como sí mismo auténticamente personal, como posible Existencia, sólo puede alcanzarse - de nuevo la paradoja - en interrelación con lo que no es uno mismo. De igual forma que, en la consideración inmanente de la enfermedad, los distintos niveles objetivos sólo alcanzaban su configuración mediante la interrelación del sujeto enfermo con lo que Jaspers llama el mundo, en la consideración trascendente de la enfermedad también se necesita inevitablemente de lo otro. La vivencia de la enfermedad como símbolo de la Existencia sólo puede darse en comunicación con el otro y en función de la Trascendencia (Traszendenz) ${ }^{47}$. Esta Trascendencia no está en Jaspers personalizada en un Dios, como sucede en el caso de Kierkegaard ${ }^{48}$, sino que es siempre inobjetiva. Es la imagen, la cifra, de lo que siendo lo radicalmente otro (das schlechthin Andere), nos configura inevitablemente ${ }^{49}$.

La constatación de que la racionalidad y la no racionalidad de lo real son ambas opciones legítimas pero indecidibles, ha forzado a un creciente número de teóricos del conocimiento a la denuncia, primero, de las ilusiones de la ciencia, y, segundo, a la toma en consideración (por diversos fines: búsqueda de fuentes de ideas, constatación de los límites del actuar científico, conocimiento de las carencias de la ciencia...) de formas de conocimiento indirecto que asuman el pensamiento antinómico ${ }^{50}$.

No es extraño, por tanto, que haya prendido en la comunidad científica una actitud que Gell-Mann ha calificado con el nombre de «odiseica» — por conjuntar lo que

\footnotetext{
46 Jaspers se refirió a la Existencia en una de sus últimas obras con las siguientes palabras: «El fundamento del ser-sí-mismo, la oscuridad desde la que yo salgo a mi encuentro, esto por lo que yo me produzco a mí mismo libremente, por lo que me soy regalado...Pero este fundamento, esta libertad, esto por lo que puedo ser yo-mismo, y en comunicación con otro sí-mismo hacerme verdaderamente yomismo, lo denominamos posible Existencia». Jaspers, K. (1962), Der philosophische Glaube angesichts der Offenbarung, München, Piper, p. 116.

47 «La Existencia es el ser-mismo que se refiere a sí mismo y, por tanto a la Trascendencia mediante la que se sabe producida y en la que se funda». JASPERS (1974), p. 17.

48 SAlamun (1989), p. 66.

49 «sólo hay Existencia...cuando está referida a otra Existencia y a la Trascendencia, ante la cual, como lo radicalmente otro, adquiere conciencia de no ser sólo a través de sí mismo». JASPERS (1973), II, p. 2.

50 Dupré, J. (1993), The Disorder of Things: Metaphisical Foundations of the Disunity of Science, Cambridge, Mass., Harvard University Press. Se aboga aquí por la necesidad de establecer un «promiscuo pluralismo» entre los diversos modos de conocimiento que coloque los abordajes científicos dentro de sus justos límites.
} 
Nietzsche denominaba la mentalidad «apolínea» o racional y la «dionisíaca» o irracional- que combina la preferencia lógica, la aproximación analítica y el peso de la evidencia apolíneos con la inclinación por la intuición, la síntesis y la pasión dionisíacos ${ }^{51}$.

El proceder «odiseico» pone a dialogar en la práctica científica las explicaciones causales y racionales de la ciencia y sus representaciones lógicas con lo que podría llamarse, aplicando la terminología postulada por Goodman, repesentaciones simbólicas, es decir, reconstrucciones subjetivas de la realidad desde las perspectivas de la filosofía, la mística o el arte, principalmente ${ }^{52}$.

Al elaborar estas reconstrucciones simbólicas, se vuelven a pensar los objetos sometidos previamente a reconstrucciones lógicas desde esos otros pliegues perceptivos filosóficos, místicos o artísticos. El proceso seguido consistiría en deconstruir interiormente, primero, el objeto de que se trate (la enfermedad en nuestro caso) y realizar, a continuación, una síntesis abstractiva personal de los elementos esenciales del mismo, informándolos en una nueva unidad global que permita ver lo representado bajo una luz distinta de la que habitualmente tiene para él en su práctica cotidia$\mathrm{na}^{53}$. Tanto en la deconstrucción como en la síntesis abstractiva de las representaciones simbólicas las paradojas de contradicción (A es A y no A) y de incompletitud (A no es A ni no A) juegan un papel importante.

La representación simbólica permite, por ejemplo, llegar a inteligir, a través de la lectura de Jaspers, cómo la enfermedad puede devenir situación límite (inteligir no consiste en seguir los pasos de un razonamiento lógico-causal hasta alcanzar el resultado de su entendimiento, sino en -empleando la terminología jaspersiana - sentir esa idea integrada en nuestro pensamiento como si nos hubiera sido dado como un regalo). Pero sin olvidar que estas representaciones son además precisamente eso: representaciones, es decir, no son reproducciones fotográficas, sino nuevas visiones más o menos fieles al modelo del que parten (en este caso, la idea jaspersiana de la situación límite como llamada a la Existencia) en las que siempre hay resonancias distintas de las del pensamiento originario. Si los modelos se multiplican (es decir, si se toman en consideración otras diferentes aproximaciones al significado de la enfermedad) y el grado de infidelidad a los mismos sobrepasa un cierto límite, la reconstrucción simbólica pasa a ser una verdadera creación novedosa, pudiendo emerger con ella una nueva forma de consideración simbólica de la enfermedad ${ }^{54}$.

\footnotetext{
51 GELL-MANN (1995), p. 15.

52 Goodman, N. (1976), Los lenguajes del arte, trad. esp., Barcelona, Seix Barral, pp. 21-58.

53 Estos pasos son, básicamente, los señalados por Goodman para la creación artística. Moulines, por su parte, sostiene que son los mismos que se deben llevar a cabo en la elaboración de metateorías. Moulines, C.U. (1990), «La metaciencia como arte». En: H. HAKEN; D.R. HofsTADLER; B. MANDELBROT et al., Sobre la imaginación científica, Barcelona, Tusquets, 39-62; p. 48.

54 Debe tenerse en cuenta que el proceso de elaboración de representaciones lógicas en ciencia es similar al que se acaba de describir para la producción de representaciones simbólicas. Las diferencias entre uno y otro residen en que en las lógicas: a) las deconstrucciones y reconstrucciones se basan en la
} 
La elaboración de representaciones simbólicas también puede trazarse, desde la idea de la información a partir del ruido, como un proceso de emergencia del orden mediante el dominio del azar por el $\operatorname{azar}^{55}$. Desde esta perspectiva, una serie de sucesos (las ideas de los distintos modelos de que hablábamos arriba - p. ej., el jaspersiano-, pero también sonidos, imágenes, recuerdos, imaginaciones, sueños...), reunidos aleatoriamente sin ningún orden aparente y formando un torbellino indescriptible (el ruido), van acumulándose en el sujeto produciendo un creciente desorden. En un momento dado, azarosamente, el pensamiento alcanza un estado de desorden óptimo que le permite descubrir, mediante las deconstrucciones y reconstrucciones de esos sucesos desde la antinomia, relaciones coherentes entre ellos (coherentes en un nivel de percepción en el que las significaciones son distintas del estado perceptivo normal). Estas relaciones hacen que el ruido pase a ser información y aparezca —emerja- de ella un estructura perceptible, un orden: la representación simbólica. Orden que se transforma de nuevo acto seguido en ruido susceptible de actuar en otros lugares (otros niveles del pensamiento, otros sujetos...) ${ }^{56}$.

No hay que olvidar que el fenómeno de la aparición del orden desde el desorden en la observación científica de la naturaleza, tal y como se describía más arriba cuando se hablaba del conocimiento directo, es un proceso distinto del que se produce en

no contradicción y b) su expresión busca la unicidad del sentido y la precisión del contenido; en las simbólicas en cambio: a) las deconstrucciones y reconstrucciones no excluyen la contradicción y la incompletitud y b) su expresión busca la multiplicidad del sentido y la ambigüedad del contenido.

55 Sobre la transformación del ruido en información en el pensamiento simbólico, véase: SPERBER D. (1988), El simbolismo en general, trad. esp., Madrid, Anthropos, p. 114; y ATLAN (1991), pp. 129-35. Sobre la autoorganización a nivel cerebral, véase: KELSO, J. A. S; HAKEN, H. (1995), «New laws to be expected in the organism: synergetics of brain and behaviour». En: M.P. MURPHY; L. A. J. O'NEILL (eds.), What is Life? The Next Fifty Years. Speculations on the Future of Biology, Cambridge, Cambridge University Press, 137-160.

56 Las representaciones simbólicas cuando alcanzan determinado grado de calidad (de infidelidad a los modelos que forman parte de las ideas contenidas en el ruido), se transforman en creaciones. La creación artística es también, pues, un proceso de elaboración de representaciones simbólicas. Testimonio de ello son las siguientes palabras del poeta José Hierro en respuesta a la pregunta sobre su técnica creativa: «Mi técnica consiste en partir de una serie de datos confusos, almacenados día tras día [el ruido]. Apelo a ello en varios momentos. El conjunto se va aclarando, sedimentando [formación del desorden óptimo del pensamiento], y acaba cristalizando en un poema [orden por el dominio del azar por el azar]». SASTRE, L. (1959), «Amarillo, en Moguer con José Hierro», Indice, n. ${ }^{\circ} 122,1959$, p. 8. Cit. según: Hierro, J. (1991), El libro de las alucinaciones, ed. de D. CAÑAS, $2^{\circ}$ ed., Madrid, Cátedra, p. 103. La forma en que se produce la creación ha sido una de las preocupaciones que más se ha reflejado en la obra poética de Hierro. La siguiente estrofa del poema titulado «Alucinación en Salamanca» da cuenta de dicha inquietud: «Quién sabe qué decían / las olas de esta piedra [el ruido]. / Quién sabe lo que hubiera / -antesdicho esta piedra / si yo hubiera acertado la palabra precisa / que pudo descuajarla del futuro. Cuál era / ayer- esa palabra / nunca dicha. Cuál es / esa palabra de hoy / que ha sido pronunciada [la variabildad del desorden óptimo del pensamiento], / que ha ardido al pronunciarla [el orden momentáneo, el poema], / y que ha sido perdida definitivamente [la conversión del orden en ruido]». HIERRO (1991), p. 109. Lo situado entre corchetes son, claro es, añadidos míos. 
la generación del pensamiento simbólico. En el primer caso se trata de experimentos de acontecimientos naturales de los organismos vivos interpretados desde teorías físicas y matemáticas; $\mathrm{y}$, en el segundo, de experiencias en el orden del lenguaje y del pensamiento. Sin embargo, la expresión de orden desde el desorden pasa a designar procesos muy similares si en el primer caso nos trasladamos del nivel descriptivo al metadescriptivo, esto es, al de la descripción de la descripción, pues entonces pasamos a confrontar la aparición de representaciones lógicas con la de las representaciones simbólicas ${ }^{57}$. Las diferencias consisten, me atrevería a decir que casi únicamente, en el empleo, por parte de las primeras, de parámetros lógico-causales y de un lenguaje unívoco y preciso; mientras que las segundas no descartan los parámetros antinómicos y buscan la polisemia del lenguaje $\mathrm{e}^{58}$.

Dos son, a tenor de lo dicho las páginas anteriores, los caracteres del conocimiento indirecto de la enfermedad en el pensamiento de Jaspers que se siguen distinguiendo en la noción de conocimiento arracional desarrollada por la reciente filosofía del conocimiento:

1. Su delimitación simbólica y antinómica: que, en Jaspers, se concretaba en la idea de la enfermedad como trasunto de la Existencia en tanto situación límite y, en el pensamiento actual, se explicita a través de la noción de las representaciones simbólicas de la enfermedad.

Y 2. La consideración de que sólo se produce en tanto conjunción compleja con lo ajeno al hombre: con eso que Jaspers denominaba lo radicalmente otro (la Trascendencia) y que en el pensamiento actual ha pasado a analizarse desde nociones como las del desorden o del ruido.

\section{LA ARTICULACION DE LAS DOS FORMAS DE CONOCIMIENTO}

Dado que la realidad puede ser no contradictoria, pero también puede ser antinómica, es necesario que en la aprensión de una realidad determinada, como pueda ser la de la enfermedad, se realice una conjunción de las dos formas de conocimiento que encarnan dichas posibilidades: el directo, al que el conocimiento científico sirve de principal referente; y el indirecto, al que el saber de los campos filosófico, místico y artístico puede tomarse como representante.

57 ATLAN (1991), p. 134.

58 Véase la nota 54. 


\subsection{Los requisitos de la articulación}

Para Jaspers, la relación entre las dos formas de conocimiento de la enfermedad pasa, en primer lugar, por una precisa diferenciación de sus respectivos campos de actuación. El conocimiento indirecto se significaría sobre todo por una no separación entre lo conocido (la enfermedad, en el caso que nos ocupa) y el que conoce. En el conocimiento científico el que conoce está separado del objeto, en el indirecto el sí mismo del cognoscente debe estar en el objeto (la idea de la enfermedad como experiencia del límite sólo puede ser elucidada desde la identificación con el objeto, desde el sentir concitada la propia Existencia en la intelección de la enfermedad como situación límite $)^{59}$.

No hay que perder de vista que para él lo verdaderamente importante no consistía tanto la colocación de los límites de la ciencia más acá o más allá, cuanto en el establecimiento mismo de una frontera nítida y definida entre el conocimiento directo y el indirecto ${ }^{60}$. La ciencia no tiene limitaciones dentro del nivel intramundano (material), pero, para Jaspers, es imprescindible que permanezca recluido en este ámbito por constituir su límite esencial. Transponerlo equivaldría a intentar ofrecer sólo con la ciencia una imagen completa de la realidad como todo, lo cual daría lugar a una realidad falseada (en nuestro caso una noción de enfermedad falseada) y a una desvirtuación de la ciencia ${ }^{61}$.

La articulación de los modos de conocer (el científico, en tanto modelo de conocimiento directo; y el antinómico como prototipo del indirecto) y el consiguiente establecimiento de una neta frontera entre ellos sigue estando entre las preocupaciones epistemológicas actuales. Esta distinción entre el conocimiento directo y el indirecto de la realidad en general y, por tanto, también de la realidad específica de la enfermedad, tiende a hacerse en el pensamiento actual mediante el reconocimiento de esquemas causales (externos o explicativos e internos o interpretativos) en el primero y de esquemas acausales (iluminadores o, lo que es lo mismo, completamente explicativos) en el segundo. Los cuales se acompañan, como se dijo más arriba, de un uso de la razón (en tanto pensamiento lógico) apoyado en la no contradicción y de un lenguaje preciso, en el conocimiento directo; y de un uso de la razón (también en tanto pensamiento lógico, pero que usa la lógica a otro nivel) que no excluye la con-

\footnotetext{
59 JASPERS (1973), I, p. 320.

60 JASPERS, K. (1951), Rechenschaft und Ausblick. Reden und Aufsätze, München, Piper, p. 328. La preocupación por la nitidez de la línea fronteriza fue la causa de las polémicas de Jaspers con Husserl y con Rickert, notorios ejemplos, según la visión jaspersiana, del rechazable proceder de intentar convertir el pensamiento filosófico en ciencia. Cf. JASPERS (1977), pp. 35-36; y SANER (1982), pp. 37-38.

61 Collins, J. (1981), «Jaspers on science and philosophie». En: Paul Arthur SCHILPP (ed.), The Philosophy of Karl Jaspers, $2^{\circ}$ ed., La Salle, Illinois, Open Court, 115-140; p. 126.
} 
tradicción (lo que denominábamos arracionalidad) y de un lenguaje ambiguo, en el conocimiento indirecto ${ }^{62}$.

Además, para la epistemología actual el conocimiento científico tiene unos objetivos distintos de los del conocimiento indirecto ${ }^{63}$ : la ciencia busca el dominio y transformación de la naturaleza, del hombre y de la sociedad; el conocimiento indirecto tiene como fin la explicación total, conseguir la más perfecta intelección de la naturaleza, del hombre y de la sociedad. En el caso concreto de la enfermedad, el conocimiento directo tendría por fin alcanzar la mayor operatividad sobre la enfermedad, esto es, tendría por objetivo la curación. El conocimiento indirecto buscaría conseguir, por su parte, la explicación total de la enfermedad, esto es, lograr su intelección de la forma más profunda posible.

El estilo actual de pensamiento, por consiguiente, sigue sosteniendo la necesidad de unos claros límites entre las dos formas (la objetiva y la inobjetiva) de conocimiento, pero con dos diferencias con respecto a Jaspers: la mayor amplitud concedida al espacio científico y la mayor flexibilidad del límite ${ }^{64}$. En la teoría de la ciencia actual tienen carácter científico muchas cosas que no cumplirían los criterios jaspersianos. Y, además, el límite entre ambos terrenos se contempla con una cierta ductilidad, pues se tiene en cuenta que, en su desarrollo, tanto el conocimiento directo como el indirecto intenten sobrepasar sus propios límites: la ciencia, con la formulación de teorías arriesgadas y, sobre todo, mediante el desarrollo de nuevos métodos de observación y de cálculo que permitan acceder a nuevos estratos de la realidad del enfermar hasta entonces pertenecientes al terreno de lo no conceptualizable; el conocimiento indirecto, a su vez, mediante ardides y sutilezas del lenguaje que le posibiliten arañar el terreno reservado a lo analítico y lo conceptual.

La articulación de los dos métodos del conocer necesita, para Jaspers, en segundo lugar, de una clarificación con respecto a sus respectivas carencias. Jaspers señala estas lagunas en los principios de su Philosophie. Allí afirma que el proceder científico garantizaría la veracidad (Richtigkeit) del conocimiento de la enfermedad, pero no la importancia (Wichtigkeit) de tales conocimientos ${ }^{65}$. Con otros términos: la ciencia confiere validez, pero tan sólo en campos muy específicos de la enfermedad. Complementariamente, el conocimiento indirecto aclararía el valor (el sentido exis-

62 Para una comparación entre los distintos criterios que sirven en el momento actual para delimitar el ámbito de actuación de la ciencia, véase: WEINERT, F. (ed.) (1995), Laws of Nature. Essays on the Philosophical, Scientific and Historical Dimensions, Berlin, W. de Gruyter.

63 ATLAN (1991), p. 311.

64 Ibidem, pp. 308-312.

65 JASPERS (1973), I, p. XLII. 
tencial, por ejemplo) de la enfermedad, pero no otorgaría ningún tipo de certidumbre respecto de la misma.

Asimismo, las carencias de las dos formas de conocer la realidad de la enfermedad se siguen constatando en el pensamiento actual, aunque por caminos algo distintos de los seguidos por Jaspers. Con relación al conocimiento científico, las fallas se hacen radicar en dos circunstancias: en la fundamentación de la eficacia del conocimiento científico en la restricción del campo de acción a aquello a lo que el método científico puede aplicársele ${ }^{66}$; y en la tendencia cada vez más acusada de la ciencia a basar su investigación en «artefactos», esto es, no en objetos surgidos de la naturaleza sino en objetos artificiales elaborados en el laboratorio ${ }^{67}$.

Por su parte, la carencia del conocimiento indirecto se lozalizaría en su propia expresión, ya que lo verdaderamente esencial de esta forma de conocimiento no puede ser dicho con palabras, pero éstas son indispensables para expresarlo (la expresión de la enfermedad como experiencia del límite nunca puede agotar lo que realmente es, únicamente esclarecerlo fugazmente). Por ello, su expresión no puede ser sino ambivalente y oblicua, realizándose en un continuo movimiento que va del descubrir al velar y, de ahí, de nuevo al descubrirr ${ }^{68}$.

Por último, la articulación de los modos de conocer necesita, según Jaspers, clarificar cuál puede ser la utilidad que cada uno de ellos tiene para el otro. El conocimiento indirecto puede suponer para el conocimiento científico de la enfermedad un acicate para la investigación, independientemente de cualquier motivo ligado a la utilidad o al provecho; una suerte, por tanto, de impulso incondicionado para el saber científico. Como impulsor —en tanto erweckende Philosophie (filosofía suscitadora) - el conocimiento indirecto también puede hacer surgir una serie de bosquejos generales en

66 Atlan ejemplifica esta carencia muy gráficamente con el conocido chiste del borracho que ha perdido la llave de su casa y al preguntarle un amigo por qué, habiéndola perdido lejos de allí, se empeña en buscarla justamente debajo de ese farol, aquél responde que porque es el único sitio donde hay luz. ATLAN (1991), p. 324

67 En el caso de la biología y de la medicina esta circunstancia, instaurada previamente en la física y en la química, ha empezado a manifestarse de forma espectacular en las recombinaciones genéticas. Mediante ellas, por primera vez, seres vivos utilizados en la investigación no son ya objetos naturales sino creados artificialmente por necesidades técnicas o industriales. ATLAN (1991), pp. 324-325. Con respecto a la investigación de la ciencia sobre «artefactos», ya hace cierto tiempo que Bachelard llamó la atención sobre el contrasentido entre el carácter constructivista de la puesta en práctica del «nuevo espíritu científico» y la convicción por parte del investigador de que lo que estaba efectuando era con todo un proceso de explicación de lo real. Bachelard encontraba que precisamente en esta convicción, a pesar de ser sólo un producto de la psicología del sujeto, residía el impulso para la creación de ciencia. BACHELARD, G. (1991), Le nouvel esprit scientifique, $4^{\circ}$ ed., Paris, Quadrige/PUF, pp. 18-20.

68 ATLAN (1991), pp. 308-312. 
relación con la enfermedad, entendidos estos esbozos no como propuestas concretas a elegir sino como posibilidades abiertas alumbradoras de futuras hipótesis científicas ${ }^{69}$.

Correspondientemente, el conocimiento científico de la enfermedad, al hacérsele evidente los límites que no puede traspasar (el conocimiento del hombre en tanto libertad incondicionada), indica al conocimiento indirecto, para Jaspers, su punto de partida ${ }^{70}$.

La clarificación de los recíprocos beneficios, es también uno de los requisitos de la correcta articulación de los modos de conocer para la actual teoría del conocimiento. Según Popper, ideas surgidas del conocimiento indirecto podrían transformarse, aunque de forma oblicua y oscura, en teorías científicas, en especial si éstas tienen un cierto grado de universalidad: «Para tener una imagen o modelo de esta evolución casi inductiva de la ciencia podemos representarnos las diversas ideas e hipótesis como partículas suspendidas en un fluido. La ciencia susceptible de contrastación es el precipitado de dichas partículas en el fondo del recipiente, donde se depositan en capas (de universalidad); el espesor del depósito crece con el número de capas, y cada capa nueva corresponde a una teoría más universal que las situadas debajo de ella. Como resultado de este proceso, es posible que el crecimiento de la ciencia llegue a alcanzar ideas que antes se encontraban flotando en regiones metafísicas más altas, con las que establece contacto y las hace asentarse. Tenemos ejemplos de estas ideas en el atomismo, en la idea de un «principio» físico —o elemento últimoúnico (del cual se derivan todos los demás), en la teoría del movimiento terrestre (al cual se opuso Bacon como ficticio), en la antiquísima teoría corpuscular de la luz, y en la teoría de la electricidad como fluido (que ha revivido en forma de hipótesis del gas de electrones de la conducción metálica). Todos estos conceptos e ideas metafísicas pueden haber ayudado, incluso en sus formas más primerizas, a ordenar la imagen del mundo que tiene el hombre, $y$, en algunos casos, han llevado a predicciones con éxito. Pero una idea de este tipo adquiere ciudadanía científica solamente cuando se la presenta en forma falsable: esto es, sólo cuando se ha hecho posible decidir entre empíricamente entre ella y otra teoría rival $\gg^{71}$. En el campo concreto de la medicina y la enfermedad, Fleck estudió, hace ya algún tiempo, cómo la pervivencia de la protoidea (Uridee) de la sangre corrupta de los sifilíticos, de carácter principalmente creencial y presente con diversas modificaciones a lo largo de los siglos XVI, XVII y XVIII, fue uno de los impulsos fundamentales, aunque siguiendo un camino oblicuo y oscuro, para el descubrimiento de la reacción de Wassermann ${ }^{72}$. La conversión de ideas metafísicas o creenciales en hechos científicos y la reconstrucción del enreve-

69 JASPERS (1973), I, p. 321.

70 El filósofo, afirmaba Jaspers, debía tener siempre sólidos conocimientos en alguna ciencia con el fin de percibir claramente sus limitaciones. Ibidem, I, 318-321.

71 POPPER, K. (1962), La lógica de la investigación científica, trad. esp., Madrid, Tecnos, pp. 258-259.

72 FLECK, L. (1979), Genesis and Developement of a Scientific Fact, trad. ingl., Chicago, The University of Chicago Press, pp. 12-14. 
sado camino que a veces se sigue en la génesis de esos hechos a partir de algún substrato creencial o metafísico, como pasó con la reacción de Wassermann, puede hacer reconocer el valor de las prácticas científicas en torno a la enfermedad por los resultados prácticos a que den lugar, sin que haga ninguna falta creer además en la verdad absoluta, por científica, de sus productos.

Correspondientemente, el conocimiento científico, por el rigor de su proceder analítico y por su eficiencia en la reconstrucción de una realidad material mediante su descripción en un lenguaje universal, puede tener una influencia positiva en la consideración indirecta de la enfermedad, pues sirve de modelo para la ordenación, hasta donde es posible llevarla a cabo, de las experiencias sensibles en ideas expresables, sin que en este camino se pierda su sentido ${ }^{73}$. Este influjo puede servir además para ayudar a contemplar la contradicción en la consideración de la enfermedad sin subterfugios, pero también sin desorientarse en ella, enriqueciéndose en el vaivén que va desde la contemplación de la antinomia a los intentos por reducirla.

\subsection{Los instrumentos de la articulación}

Cuál es, finalmente, el modo en que, según Jaspers, debe establecerse una articulación entre el conocimiento directo y el indirecto en relación con la enfermedad, que mantenga su diferenciación y, a partir de la constatación de sus carencias respectivas, posibilite su mutuo provecho? Si, siguiendo la línea directriz de este trabajo, respondemos a esta pregunta desde la idea del Envolvente, la respuesta es clara: sólo por medio de la Razón (Vernunft) se puede producir su conjunción sin caer en un sincretismo esterilizante ${ }^{74}$.

La Razón, en tanto principio vinculante de las formas de conocimiento de la enfermedad, quedaría definida por el desempeño de tres funciones:

Primero, por su función dinámica, que haría ver las carencias de los dos modos de conocer. La Razón se mueve siempre de una a otra forma de conocimiento (entre la

73 Atlan (1991), p. 318.

74 Hay que tener presente que en Jaspers hay una separación muy nítida entre el pensamiento lógico (Verstand) y la Razón (Vernunft). La función del pensamiento lógico permite el entendimiento objetivo, unívoco y no contradictorio. La Razón en Jaspers debe entenderse como el logos creador, el principio que nos permite vincular adecuadamente el pensamiento lógico con el pensamiento trascendente antinómico o arracionalidad (que también usa la lógica, pero a otro nivel). La Razón es lo que mueve siempre a criticar lo adquirido, lo arbitrario, lo dogmático, lo presupuesto. Se apropia para ello del pensamiento lógico, sin tener las limitaciones de éste. El pensamiento lógico fija, limita y objetiva lo sabido; la Razón abre, mueve, no se detiene en lo sabido. Pero la Razón no da ningún paso sin el pensamiento lógico. JASPERS (1983), pp. 116-118. Teniendo esto en cuenta, Razón se escribirá aquí con mayúsculas cuando signifique dicho principio conector entre la racionalidad (la razón no contradictoria, el pensamiento lógico o Verstand) y la arracionalidad (la razón antinómica). 
autoridad del conocimiento objetivo de la enfermedad y la excepción de lo inteligido sobre ella por el conocimiento indirecto $)^{75}$. En esta fluctuación entre - usando los términos de Jaspers - la ley del día (Gesetz des Tages) y la pasión de la noche (Leidenschaft zur Nacht), la razón siempre se orienta hacia lo nuevo, hacia lo extraño (das Fremde). Por ella se removiliza todo lo asumido. Supone siempre posibilidad de incremento de saber, de apertura a nuevas formas de ver la enfermedad ${ }^{76}$.

Segundo, por su función diversificadora, que mantendría la neta diferenciación de las formas de conocimiento. La Razón garantiza la permanencia independiente de ambos modos de conocer la enfermedad, impidiendo que se hagan unos meros subordinados de los otros. Esta simultánea presencia posibilitada por la Razón no tiene el carácter de un mero agregado, sino el de un conflicto permanente debido a las coerción mutua ${ }^{77}$. La razón es el aval de la autenticidad de estos conflictos ${ }^{78}$.

$\mathrm{Y}$, tercero, por su función unificadora, que pondría de relieve el mutuo provecho de las dos vías del conocer. La Razón es la voluntad total de comunicación (der totale Kommunikationswille). Desea conservar no sólo todo lo que es, también todo lo que puede ser. Por ello posibilita la conexión de los modos de abordar la enfermedad para que ningún fragmento de saber se pierda ${ }^{79}$. La Razón permite establecer, así, unidades o identidades entre diversos aspectos determinados de las dos formas de conocimiento, las cuales tienen siempre carácter de interinidad o provisionalidad (Vorläufiges), que pueden servir para abrir nuevas perspectivas en cada campo ${ }^{80}$.

Desde la Razón con esta triple función, puede pensarse el todo de la enfermedad, pero no en tanto realidad objetiva. La enfermedad como todo sería una realidad velada ${ }^{81}$, que sólo podría desvelarse siguiendo dos caminos - el inmanente o directo y

75 «La Razón se dirige hacia lo que le es extraño desde el punto de vista del pensamiento científico. Se vuelve -esperando la verdad- hacia la excepción y la autoridad. Tampoco se queda en ellas como si estuviera en la meta y permaneciera en la paz». JASPERS (1974), p. 49.

76 «la Razón (...) pone en movimiento lo que asume. Porque pregunta y se expresa, provoca inquietud. Por tanto, la Razón es la posibilidad, común a los surgimientos originarios, de desarrollarse, de abrirse, de devenir puros, de que se expresen y se pongan en relación». Ibidem, p. 50 .

77 «Los modos de los sentidos de la verdad no son un agregado sin relación. Están en conflicto ante las posibilidades de coerción mutua. Toda verdad se transforma en una falsedad cuando, en contra de su propia coherencia significativa, se hace dependiente de otra verdad y tolera que la viole». Ibidem, p. 34 .

78 «La Razón posibilita la autenticidad de los conflictos y las luchas que actúan en y entre los modos del Envolvente». Ibidem, pp. 50-51.

79 «La Razón es lo que ensambla en todas las situaciones para aproximarse a esta unidad. La razón desea anular lo que existe siempre en la dispersión de cosas entre sí indiferentes en el movimiento de una recíproca participación (...) Toda falta de relación debe cesar. Nada debe perderse». Ibidem, p. 48.

80 «La Razón es también, respecto de la exigente unidad, una interinidad que pertenece al ser temporal y que es forzada por él. Pero la Razón no puede encontrar la paz en ninguna interinidad aunque esta tenga un aspecto grandioso». Ibidem, p. 49.

81 Algunas imágenes empleadas por Jaspers para esclarecer la idea del Envolvente, como por ejemplo la de que «el Envolvente nunca se presenta a sí mismo, pero todas las cosas se presentan en él», o la 
el trascendente o indirecto- articulados pero contrapuestos. Al ser caminos diferentes de los que tenemos experiencia de forma separada, la enfermedad sólo se desvelaría parcialmente con cada uno, en fragmentos alternativos no superponibles ${ }^{82}$.

En la epistemología actual también encontramos instancias que, de forma similar a la razón jaspersiana, permiten relacionar los distintos modos de conocer la enfermedad, de tal forma que, sin dejar de percibir la diferencias entre ellos ni sus respectivos límites, hagan posible su mutuo aprovechamiento. Una de las nociones más estimulantes a este respecto es la del juego ${ }^{83}$.

El juego, en tanto instancia conectiva, permite aceptar diversos sistemas interpretativos de la enfermedad (el directo y el indirecto) sin entremezclar sus distintas reglas. El juego permitiría así mantener la racionalidad lógica o científica en la consideración del enfermar sin cerrar las puertas a otras formas diferentes de emplear la racionalidad en su conocimiento (esa «racionalidad» entre comillas o arracionalidad, que designaba la forma de pensar la enfermedad desde la antinomia $)^{84}$.

de que «el Envolvente se anuncia en los objetos presentes y en el horizonte, pero nunca se deja captar como objeto», pueden ayudar a captar la idea que tendría la enfermedad en tanto todo. JASPERS (1983), pp. 39 y $781-782$

82 La enfermedad como «realidad velada», aun con matices distintos, tiene cierta semejanza con el «principio de la puerta giratoria» (Drehtürprinzip) de Viktor von Weizsäcker. Según este principio, nuestra relación con el mundo posee un carácter circular que hace que todo lo que en un momento dado percibo en el mundo (o en el hombre enfermo) siguiendo un método de conocer me oculta todo lo que no veo en el mundo (o en el hombre enfermo) mediante este método, y que lo así hecho visible me queda a su vez oculto cuando, al seguir otro método de conocimiento del mundo (o del hombre enfermo), noto otras cosas que antes no percibía. Weizsäcker, uno de los fundadores de la medicina psicosomática en Alemania, aplicó este principio a la percepción de lo somático y de lo psíquico: la atención hacia lo somático impedirá percibir lo psíquico y la atención hacia lo psíquico vedaría la percepción de lo somático. El sentido de la enfermedad sólo podría ser obtenido integrando esos dos modelos en un cuadro clínico total. Para von Weizsäcker, la psique y el soma no eran dos realidades que interactuaban una sobre otra, sino formas en las que se muestra un fondo misterioso que se presenta al observador de forma alternante en cada una de ellas. Cf. WEIZSÄCKER, V.v. (1956), El hombre enfermo. Una introducción a a la antropología médica, trad. esp., Barcelona, L. Miracle, pp. 303-308. Una sucinta pero provechosa descripción de las ideas de von Weizsäcker se encuentra en: LAIN ENTRALGO, P. (1982), El diagnóstico médico. Historia y teoría, Barcelona, Salvat, pp. 163-172. Las teorías de von Weizsäcker no sólo son aplicables al campo de la psicosomática, también tienen implicaciones para el análisis de la teoría del conocimiento y la teoría social. A este respecto, véase las diferentes contribuciones contenidas en BENZENHÖFER, U. (ed.) (1994), Antropologische Medizin und Sozialmedizin im Werk Viktor von Weizsäckers, Frankfurt, Lang.

83 Aplicamos en este punto a la articulación de los modos de conocer la enfermedad la noción -el juego- que a Atlan le sirve para la intercrítica entre la ciencia y el mito. ATLAN (1991), pp. 337-384.

84 Ibidem, p. 337. 
La articulación de los modos del conocimiento de la enfermedad sería un juego abierto, pero no por ello desprovisto de reglas. Las reglas que lo harían practicable son fundamentalmente dos y ambas de orden negativo. Primera: que no se debe mezclar las reglas de los distintos juegos (las de los sistemas interpretativos de la enfermedad directos con las de los indirectos) ${ }^{85}$. Y segunda: que la articulación por el juego no debe ser tenida como un conocimiento acabado, como una metateoría estable, sino como algo perteneciente al orden práctico y, por lo tanto, siempre modificable; es decir, que no hay que hacer del juego como instancia de conjunción un contenido de saber fijado, sino preservarlo como un actuar modificable y, por tanto, como una práctica siempre imperfecta y siempre mejorable ${ }^{86}$.

El juego, en tanto principio práctico de relación de las formas de aproximación a la enfermedad, mantendría las tres funciones que veíamos en la Razón jaspersiana: la dinámica, la diversificadora y la unificadora ${ }^{87}$.

El juego, en su función de dinamizador, permite pasar de un modo a otro en el conocimiento de la enfermedad y ver las carencias de cada uno (la fundamentación de su eficacia en la restricción del campo de actuación y el basamento de su investigación sobre «artefactos», por parte del directo; y la inexpresabilidad de lo esencial, por parte del indirecto).

Mediante el juego pueden establecerse también los mutuos beneficios de la interrrelación de las dos formas de conocer (las ideas metafísicas como fuente de ideas científicas, el rigor analítico como referente de la expresión de las experiencias sensibles), ocasionando con ello la percepción de la unidad de la noción de enfermedad al proporcionar modos de adecuación entre lo abstracto (lo científico, lo teórico) y lo concreto (lo real, lo percibido).

El juego, por último, al considerar las diferencias entre las vías de conocimiento de la enfermedad (la objetiva dedicada a la curación, la inobjetiva aplicada a la explicación aboluta), fuerza también a advertir que, en otras ocasiones, la distancia entre lo abstracto y lo concreto es muy grande y, con ello, evidencia la diversidad de la idea de enfermedad.

Como desde la Razón, la enfermedad puede ser pensada como todo también desde el juego. El conocimiento de la enfermedad como todo aparecería aquí, con esa orientación exclusivamente práctica, como un metajuego (un juego de juegos) con unas metarreglas (negativas, como quedó dicho) mediante el cual juegos de distintas reglas (seguimiento de esquemas causales, uso de la razón apoyado en la no contradicción y un lenguaje unívoco, por parte del directo; y seguimiento de esquemas acausales, uso de una razón que no excluye la contradicción y un lenguaje polisémico, por parte del indirecto) se ponen en situación de jugar entre sí, sin caer en un

\footnotetext{
85 Ibidem, p. 438.

86 Ibidem, p. 318.

87 Ibidem, p. 283. 
sincretismo falso que mezclaría cartas, fichas y tableros e impediría empezar a ju$\operatorname{gar}^{88}$. El conocimiento de la enfermedad como todo quedaría así anunciado en esos dos caminos de forma siempre parcial, pero no podría quedar enunciado de forma estable. En este sentido, la enfermedad en tanto todo podría considerarse como una «irrealidad real» o como un «fenómeno transicional» ${ }^{89}$.

\section{EPILOGO}

El pensamiento jaspersiano en torno a la teoría del conocimiento de la enfermedad, bien que con otras formulaciones y conceptos, sigue teniendo, como se ha intentado mostrar en las páginas precedentes, vigencia en el pensamiento actual, especialmente en los siguientes puntos:

1. La consideración de un conocimiento directo u objetivo de la enfermedad, el cual se estratifica en una serie de niveles de forma abierta (dejando franca la posibilidad a nuevos niveles) y armónica (impidiéndose la absolutización de unos sobre otros). En Jaspers los límites entre los niveles se establecen de una manera imprecisa y arbitraria a través de su presunta evidencia por parte del

88 Ibidem, p. 119

89 La idea del conocimiento de la enfermedad en tanto todo como metajuego parte de las nociones de Fink en torno al juego como irrealidad (Unwircklichkeit) que nos permite, siquiera momentáneamente, liberarnos de la realidad. El hombre, cuando juega, no permanece, según Fink, dentro del limitado ámbito de su interioridad, sino que sale fuera de sí en éxtasis y esclarece el mundo desde la actitud lúdica. Esta actitud le pone ante todas las posibilidades a la vez (en ese éxtasis que posibilita acceder a la totalidad del mundo). La irrealidad -los símbolos irreales del mundo (irreale Weltsymbole)- hecha presente por el juego, se transformaría en mundo real restringiendo sus posibilidades. FINK, E. (1960), Spiel als Weltsymbol, Stuttgart, W. Kohlhammer, pp. 228-230. La enfermedad como metajuego sería así una «irrealidad real» que habría que concretizar, reduciendo sus posibilidades, hasta llegar a las diversas realidades concretas de cada campo de conocimiento.

El conocimiento de la enfermedad como todo desde la idea de metajuego también sería comparable a lo que Winnicott llamaba «fenómenos transicionales» y «objetos transicionales» en sus trabajos sobre el desarrollo psíquico y el reconocimiento del «no-yo» en los niños de cuatro a doce meses. Con estos términos Winnicott designaba los fenómenos u objetos que no forman parte del cuerpo del niño (un puñado de lana, la punta de un edredón o de una sábana, una palabra, una melodía, una actitud, un objeto blando) pero que todavía no se reconocen del todo como pertenecientes a la realidad exterior. Los fenómenos y objetos transicionales suponen una especie de puente para el reconocimiento del mundo externo en el proceso del desarrolo psíquico y representan un estado intermedio entre la incapacidad del bebé para reconocer y aceptar la realidad y su creciente capacidad para hacerlo. Winnicott establece en estos fenómenos y objetos, además, la esencia de la ilusión, la cual se permite en el niño y que en la vida adulta es inherente al arte y a la religión, pero también a la locura cuando un adulto exige demasiado de la credulidad de los demás y los obliga a aceptar una ilusión que les es muy ajena. WiNNICOTT, D.W. (1995), Realidad y juego, trad. esp., Barcelona, Gedisa, pp. 18-23. 
observador. En el pensamiento actual esos límites tienden a tener una fundamentación más objetiva, por ejemplo mediante las nociones del reduccionismo débil y de la autoorganización.

2. La ineludibilidad de un segundo modo de conocimiento de la enfermedad: el conocimiento indirecto o inobjetivo, el cual, a diferencia del anterior, no excluye la antinomia. En Jaspers esta segunda modalidad se concretaba en la idea de la enfermedad como situación límite y, por tanto, como trasunto de la Existencia; en el pensamiento actual una de las formas más acabadas de expresión de este conocimiento viene dado por las representaciones simbólicas de la enfermedad.

3. La diferenciación neta entre los dos modos de conocimiento de la enfermedad. En Jaspers, la distinción entre el conocimiento científico (como modelo del conocimiento objetivo) y el filosófico (en tanto modelo del indirecto) es sumamente estricta (el conocimiento científico vendría definido por el carácter metódico, la certidumbre evidente, la validez general y la universalidad). En el pensamiento actual la diferenciación, aun siendo reconocida como necesaria, tiene unos límites más flexibles y tiende a basarse en el carácter operativo del conocimiento objetivo (con su finalidad en la curación) y en el carácter explicativo total del conocimiento inobjetivo (con la finalidad de inteligir la enfermedad desde todos los ángulos posibles).

4. La constatación de unas carencias insoslayables en cada una de las formas de conocimiento de la enfermedad. Para Jaspers el conocimiento directo garantizaba la rectitud del saber de la enfermedad, pero no su importancia; a su vez, el conocimiento indirecto aclaraba el valor (sentido) de la enfermedad, pero no otorgaba ningún tipo de certidumbre. Para el pensamiento actual las insuficiencias del conocimiento directo estriban sobre todo en que, de un lado, su eficacia se fundamenta en la restricción de su campo de actuación a aquello a lo que el método científico puede ser aplicado y, de otro, en la tendencia cada vez más acusada de la ciencia a basar su investigación en «artefactos» (creaciones de laboratorio no existentes en la naturaleza en cuanto tales). La carencia del conocimiento indirecto parte, para el pensamiento actual, en su propia expresión, ya que lo verdaderamente esencial de esta forma de conocimiento no puede ser dicho con palabras.

5. La clarificación sobre los beneficios recíprocos que para ambas formas de conocer la enfermdad puede suponer su interrelación. Para Jaspers el conocimiento indirecto actuaba de suscitador de posibilidades para el directo; el directo señalaba, por su parte, al toparse con sus limitaciones, el punto de comienzo del indirecto. Para el pensamiento actual, las ganancias mutuas se muestran, de un lado, en la eventual transformación, siguiendo caminos oblicuos y oscuros, de ideas surgidas del conocimiento indirecto en teorías cientí- 
ficas con una cierta universalidad; y, de otro, en el influjo positivo que puede tener para la consideración indirecta de la enfermedad el rigor analítico del conocimiento directo, facilitando el paso de experiencias sensibles a ideas expresables y ayudando, de esta forma, a contemplar la contradicción de la enfermedad cara a cara y sin perderse en ella.

6. La postulación de la necesidad de establecer una articulación entre las formas de conocimiento de la enfermedad sin caer en un sincretismo improductivo. Esta conjunción se llevaba a cabo en Jaspers por medio de la Razón; en el pensamiento actual una de las propuestas más estimulantes para realizar esta integración lo constituye la noción de juego, en tanto principio de pensamiento que permite conectar ámbitos de conocimiento dispares dejando de lado todo formalismo rígido, pero sin renunciar por ello a la seriedad del conocimiento.

7. La consideración, finalmente, de que la enfermedad como todo se anuncia alternativamente y de manera parcial en esas dos formas de conocimiento, pero que en tanto tal no puede enunciarse como una doctrina estable y objetiva. Esta reflexión, que en Jaspers se expresaba a través de la idea de la enfermedad como realidad velada, se sigue encontrando en el pensamiento actual a través de la idea del conocimiento de la enfermedad como metajuego (como juego de juegos, como irrealidad real).

Teniendo ante la vista esta serie de concomitancias con el pensamiento actual, la teoría del conocimiento de la enfermedad que se deriva de la teoría jaspersiana del pensamiento o, si se quiere, del Envolvente, se muestra aquí en una de sus facetas más sutiles: la de la compaginación de explicitud y vagedad. Tiene una expresión clara y concisa que, sin embargo, no excluye la coexistencia con ciertas dosis de ambigüedad. En esta coexistencia radica, probablemente, su capacidad para evolucionar y la posibilidad de ser leído desde postulados actuales (que es, a la postre, lo que se ha intentado hacer aquí con su comparación con algunas recientes aportaciones de la teoría del conocimiento).

Por último, no puedo dejar de señalar expresamente el carácter de juego —en el sentido que Fink da al término - de esta elaboración de la teoría del conocimiento de la enfermedad a partir del pensamiento filosófico de Jaspers y su reconsideración desde algunas ideas de la actual teoría del conocimiento. Juego que ha buscado esclarecer algunas cuestiones teóricas sobre la enfermedad y, a su través, esclarecer algunas cuestiones del pensamiento jaspersiano y de la actual teoría del conocimiento, al forzarles a moverse en un terreno sugerente como es el de la enfermedad. 